\title{
25 Research Square \\ Open Globe Injuries: Classifications and Prognostic Factors for Functional Outcome
}

\section{Lukas Reznicek ( $\nabla$ lukas-reznicek@gmx.de)}

Ludwig-Maximilians-Universität München: Ludwig-Maximilians-Universitat Munchen

https://orcid.org/0000-0001-8875-8892

\section{Christian S. Mayer}

Heidelberg University

\section{Ramin Khoramnia}

Heidelberg University

Jakob Siedlecki

Ludwig-Maximilians-Universitat Munchen

\section{Benedikt Schworm}

Ludwig-Maximilians-Universitat Munchen

\section{Research article}

Keywords: ocular trauma, perforating injuries, penetrating injuries, open globe injuries, ophthalmic emergency

Posted Date: September 29th, 2020

DOI: https://doi.org/10.21203/rs.3.rs-79471/v1

License: (c) (1) This work is licensed under a Creative Commons Attribution 4.0 International License.

Read Full License 


\section{Abstract}

BACKGROUND:

Epidemiology and evaluation of posterior segment involvement as a prognostic factor for functional outcome of patients with open globe injuries in a university eye clinic as a tertiary referral center in Southern Germany.

\section{METHODS:}

A retrospective analysis of 151 consecutive patients with open globe injuries who were referred to the department of Ophthalmology of the Technical University of Munich in Germany from 2004 to 2011 was conducted. Visual acuity, epidemiologic data, classification of the injuries including the ocular trauma score (OTS), performed surgeries, post-operative visual acuity and intraocular pressure (IOP) as well as correlation analyses between OTS and post-operative visual acuity were obtained.

\section{RESULTS:}

On total, 147 eyes were included in the study. The mean age of the patients was $42.9 \pm 22.2$ years, $78.2 \%$ were male, $36.7 \%$ of injuries occurred in the workplace. Thirty-eight patients $(25.9 \%)$ had intraocular foreign bodies (IOFB): $84.2 \%$ were metal objects, $5.3 \%$ organic material and $10.5 \%$ glass. On total, $51.7 \%$ of the open globe injuries were located in zone I (cornea, cornealscleral limbus), $15.0 \%$ in zone II (up to 5 $\mathrm{mm}$ posterior the sclerocorneal limbus) and $32.0 \%$ in zone III (posterior of zone 2). Affected structures were eyelids (17.7\%), cornea (74.8\%), iris (63.9\%), lens (56.5\%), sclera (48.3\%), retina (47.6\%) and optic nerve (19.7\%). Mean preoperative BCVA was $1.304 \pm 0.794 \log M A R$ and $1.289 \pm 0.729 \log M A R$ after surgery $(p=0.780)$. Patients with involvement of their posterior segment had significantly worse postoperative BCVA scores than patients without $(1.523 \pm 0.654 \log M A R$ vs. $0.944 \pm 0.708 \log M A R, p<0.01)$.

\section{CONCLUSIONS:}

Predictive factors for good visual outcome of open globe injuries are good initial visual acuity and ocular trauma affecting only zone I and II.

\section{Background}

Epidemiologic data of open globe injuries are rare in Europe. In Germany, the prevalence remains low with 3 injuries per 100,000 inhabitants a year. The frequency of those severe eye injuries has remained basically constant in the past[1].

Generally speaking, the classification of open globe injuries depends on the injury mechanism and damage of relevant structures of the eye[2-4]. Additionally to that, depending on the extent of the primary trauma, various complications such as retinal detachment, secondary glaucoma or secondary traumatic 
cataract can occur in the years following the trauma. Due to this fact, many of those patients need follow up check-ups for many years after the initial operative treatment.

In the last two decades however, advances in the surgical care of open globe injuries have improved the outcome significantly[5-7]. Nevertheless, the prognosis of those severe eye injuries, especially involving the posterior segment, remains poor and, in most cases, unpredictable[8-10]. F. Kuhn et al. were the first to categorize open globe injuries into different categories according to an ocular trauma score (OTS, table 1 ) in order to be able to look for possible prognostic factors $[11,12]$. The OTS is a number between 0 and 100 and is supposed to have a predictive value for the functional outcome (best corrected visual acuity, BCVA) of the injured eye and is calculated from the initial BCVA after the trauma and before surgery and includes also additional variables such as "globe rupture" or "relative afferent pupillary defect", details can be seen in table 1.

The goal of this study was to collect enough epidemiologic data of ocular traumas to evaluate the involvement of the posterior segment as a potential negative prognostic factor for the functional outcome of those patients.

\section{Methods}

We collected retrospective data from 151 patients who suffered from open globe injuries and were referred to the department of Ophthalmology at the Technical University of Munich in Germany in the years between 2005 and 2011.

Open globe injuries are defined as a full-thickness wound of the eye-wall with sharp or pointed objects (penetrating and/or perforating injuries), intraocular foreign bodies as well as globe ruptures. Therefore, blunt ocular traumas were distinguished from open globe injuries and were excluded.

In each case, patient data as well as circumstances of the accidents were recorded and documented. All patients were subdivided into 3 different groups according to age (see Table 2). If feasible, a full ophthalmic examination was performed including the patients' history with the mechanism of injury, the location of the wound, a description of damaged eye structures with the presence or absence of an afferent pupillary defect (APD), cataract, iris prolapse, vitreous prolapse, retinal detachment (RD) or intraocular foreign bodies (IOFB)[13]. Additionally to that, best-corrected visual acuity (BCVA) and intraocular pressure (IOP) were obtained. X-rays to exclude orbital fractures or foreign bodies were additionally obtained from each patient. The study adheres to the tenets of the Declaration of Helsinki (2008) and was approved by the Institutional Review Board of the department of Ophthalmology of the Technical University of Munich, Germany, director: Prof. Dr. Dr. Chris P. Lohmann.

\section{Classification of open globe injuries:}

Open globe injuries were classified into A: "type of injury", B: the grade (visual acuity and pupil motility [RAPD]) and C: the location of the wound ("zone classification I-III")[4, 14]: 
A: The type of injury was divided into subgroups depending on the mechanism: globe ruptures (caused by blunt trauma), globe penetration and perforation (caused by a sharp object) and penetrating injuries with intraocular foreign bodies (IOFB).

B: The grade of an ocular trauma is part of the ocular trauma score (OTS), originally published to estimate the prognosis for the visual outcome in ocular trauma of all kinds[12] (see table 1). In our study, all eyes suffered from an open globe injury, therefore the OTS category 5 was never reached. If, for example, a patient had a vision of only hand movement (equals 70 points) with a diagnosed globe rupture (minus 23 points) and retinal detachment (minus 11 points), the total sum of points is 36 points, therefore Category 2 according to the OTS score, see table 1.

C: Regarding the zone classification, the subgroups are categorized according to the location of the most posterior point of the full-thickness wound of the globe: in group I, the most posterior point is isolated to the cornea (including the corneoscleral limbus), see Fig. 1. In group II up to $5 \mathrm{~mm}$ posterior of the corneoscleral limbus into the sclera, see Figs. 2 and 3 and in group III posterior of that in group II, see Figs. 4 and 5.

Primary surgical intervention including ocular reconstruction was planned for the soonest time possible. All interventions were conducted in total intravenous anesthesia. All patients received immediate systemic antibiotics for endophthalmitis prophylaxis (Cefuroxime 1,5 $\mathrm{g}$ three-times/day for one week) and received a tetanus shot if necessary[6, 15-17].

\section{Statistical analysis}

Data were collected and analyzed using SPSS 22.0 (SPSS Inc., Chicago, IL, USA) and are presented as arithmetic mean values \pm standard deviations. Parametric (t-test) and non-parametric (wilcoxon-test) analyses were performed. A p-value $\leq 0.05$ was considered statistically significant.

\section{Results}

On total, we were able to include 147 eyes with open globe injuries referred to the clinic. Patients' characteristics, age categories and percentage of work related accidents can be seen in table 2 .

The various classifications of all globe injuries including the calculation of the OTS can be seen in table 3. The most frequent mechanism of injury was a penetrating trauma $(n=58,39.5 \%)$. Applying the zonal classification, $76(51.7 \%)$ of the open globe injuries were zone I injuries, $22(15.0 \%)$ zone II injuries and 47 $(32.0 \%)$ zone III injuries, see table 3, fig. 1-4. The most common damaged eye structures were cornea $(n=110,74.8 \%)$ followed by iris $(n=94,63.9 \%)$, vitreous $(n=88,59.9 \%)$ and lens $(n=83,56.5 \%)$, see table 4 .

Thirty-eight of 147 eyes (25.9\%) had intraocular foreign bodies (IOFBs), see fig. 5-6. Object materials were mainly metal $(84.2 \%)$ followed by glass $(n=4,10.5 \%)$ and organic material $(n=2,5.3 \%)$, see table 4 . In 36 cases $(94.7 \%)$, the IOFB could be removed successfully, whereas in 2 cases (5.3\%), the foreign body had to be left in the globe. All patients received primary care surgery, the revised ophthalmic structures during primary care surgery can be seen in table 4 . 
Mean preoperative BCVA was $1.304 \pm 0.794 \log M A R$ and $1.289 \pm 0.729 \log M A R$ after surgery $(p=0.780)$. A vitreous hemorrhage was found in $24.5 \%$ and endophthalmitis in $1.4 \%$ of all included patients. Those two cases $(1.4 \%)$ presented with post-traumatic endophthalmitis and one out of those two needed enucleation.

\section{Injuries with vs. without involvement of posterior segment}

We subdivided all included patients into two categories. The first consisted of all patients with injuries involving the posterior segment (vitreous, retina, optic nerve, $n=90$ ) and was compared to the second category of patients with injuries that did not affect structures of the posterior segment $(n=57)$. The postoperative BCVA in the first category was significantly lower than in the category of patients without involvement of the posterior segment $(1.523 \pm 0.654 \log M A R$ vs. $0.944 \pm 0.708 \log M A R, p<0.01)$. A further subdivision of patients with posterior segment involvement into those with only affected vitreous $(n=15)$ and those with affected retina and optic nerve $(n=75)$ revealed significantly better BCVA values for patients, whose posterior segment injuries had only affected the vitreous $(1.133 \pm 0.604 \log M A R$ vs. $1.603 \pm 0.638 \log M A R, p=0.013)$. Patients with open globe injuries with posterior segment involvement but only the vitreous had only tendentially but not significantly worse BCVA than patients without involvement of the posterior segment $(1.133 \pm 0.604 \log M A R$ vs. $0.944 \pm 0.708 \log M A R, p=0.308)$. Therefore, in our patients, posterior segment involvement including the retina or optic nerve are negative predictive factors for the postoperative visual outcome

\section{Discussion}

Open globe injuries are one of the most sight-threatening eye "diseases" in ophthalmology. Prior to the acute diagnosis and treatment of an open globe injury, a brief medical history should be performed to provide valuable information about the underlying responsible mechanisms and structural damages that have to be expected[18].

The spectrum of open globe injuries ranges from isolated corneal cuts to complex severe traumas involving various ophthalmic structures. Consequently, the prognosis for visual acuity also ranges from very good, such as in cases with only peripheral corneal defects, to a significantly reduced vision in cases with severe ocular trauma involving the posterior segments of the eye. Often, perforations of the cornea also affect the iris, lens and/or ciliary body. Permanent consequences can be traumatic mydriasis, iridodialysis or partial as well as total defects of the iris and secondary glaucoma. The primary aim of the surgical treatment in those cases is a watertight re-adaptation of the wound edges with fine monofilament sutures (usually 10.0 nylon sutures). If the lens capsule is damaged in the process, the consequence is usually a traumatic cataract with the necessity for a lens exchange. Because the traumatic cataract is not always visible pre- or intraoperatively, the IOL replacement is performed in a second surgery after the acute phase. In severe blunt ocular trauma, common locations for ruptures of the globe are very often the area around the limbus, the thinnest parts of the sclera directly behind the 
insertion of the rectus muscles or preformed incisions from earlier ocular interventions. The primary aim of the surgical treatment in those cases is a rapid wound closure (e.g. with 7.0 vicryl sutures). A retinal detachment can occur directly due to the trauma or secondarily because of proliferation and subsequent traction of fibro-vascular or vitreo-proliferative tissue. The aim of surgical treatment in cases of retinal detachment is re-attachment of the retina including ensured retinal holes or tears. This can be achieved with scleral buckling or with vitrectomy including the use of gas or, in some cases, silicone oil, see Fig. 3 .

The appropriate antibiotic prophylaxis for cases of open-globe injuries without presenting infection is controversial. In our clinic, we support the use of topical as well as systemic antibiotics (Cefuroxime $3 \times$ $500 \mathrm{mg} / \mathrm{d}$ ). Despite of this precaution, we observed eight patients with posttraumatic endophthalmitis over the course of postoperative treatment and follow up observation[19].

The mean age of all included patients was $42.9 \pm 22.2$ years, the vast majority of the relatively young patients were male and in working age. Thus, long-term consequences such as the inability for threedimensional vision due to significantly reduced visual acuity with consequent restrictions regarding certain types of work and workplaces has also significant economic impacts beyond the health care system alone.

Open globe injuries are a very heterogeneous group of patients. This leads to mostly individual, not standardized treatments and management of the traumas. The prognosis of visual acuity depends on the mechanism of the trauma, the location of the wound and the damaged ocular structures.

In our analysis, patients with open globe injuries affecting the posterior segment had a significantly worse BCVA outcome than patients suffering from injuries not involving the posterior segment. This difference in BCVA was reduced to a non-significant trend if the posterior segment involvement was only the vitreous. Our interpretation of the evaluated data is that damaged retina or the optic nerve in open globe injuries are associated with a significantly worse postoperative BCVA outcome.

One of the limitations is the retrospective character of our work which allows for careful but still solid interpretations and conclusions due to its relatively high number of included cases. Another aspect is the heterogeneity of the trauma patients with individualized surgical approaches with the difficulty to classify and subdivide into standardized subgroups. We tried to compensate for those limitations with a relatively large number of included patients over time and a simple classification into injuries with and without involvement of the posterior segment. Further analyses have to be done to evaluate the functional outcomes of those patients over longer time periods in order to better identify possible prognostic factors for a good visual outcome and/or following complications over time other than the initial involvement of the posterior segment.

\section{Conclusions}

In summary, we were able to identify retinal or optic nerve involvement as a negative prognostic factor for postoperative visual outcome in a large cohort of retrospectively analyzed patients with open globe 
injuries.

\section{Abbreviations}

APD: afferent pupillary defect

BCVA: best corrected visual acuity

IOFB: intraocular foreign body

IOL intraocular lens

OTS: ocular trauma score

RD: retinal detachment

\section{Declarations}

\section{- Ethics approval and consent to participate:}

The study was approved by the Institutional Review Board of the department of Ophthalmology of the Technical University of Munich, Germany, director: Prof. Dr. Dr. Chris P. Lohmann

\section{- Consent for publication:}

consent for publication was obtained

\section{- Availability of data and materials:}

data are available from the corresponding author on reasonable request.

\section{- Competing interests:}

The authors declare that they have no competing interests

\section{- Funding:}

all authors report no conflict of interest

\section{- Acknowledgements:}

not applicable 
- CM: collected data and wrote the article

- LR analyzed all data, structured and finalized the article

- RK, JS and BS finalized the article

All authors read and approved the final manuscript

\section{References}

1. Schrader WF: [Epidemiology of open globe eye injuries: analysis of 1026 cases in 18 years]. Klinische Monatsblatter fur Augenheilkunde 2004, 221(8):629-635.

2. Cherry PM: Standardized classification of ocular trauma. Ophthalmology 1997, 104(3):344-345.

3. Knyazer B, Levy J, Rosen S, Belfair N, Klemperer I, Lifshitz T: Prognostic factors in posterior open globe injuries (zone-lll injuries). Clinical \& experimental ophthalmology 2008, 36(9):836-841.

4. Kuhn F, Morris R, Witherspoon CD, Heimann K, Jeffers JB, Treister G: A standardized classification of ocular trauma. Graefe's archive for clinical and experimental ophthalmology = Albrecht von Graefes Archiv fur klinische und experimentelle Ophthalmologie 1996, 234(6):399-403.

5. Schrader WF, Viestenz A: [Severe open globe injury. New treatment concepts]. Der Ophthalmologe : Zeitschrift der Deutschen Ophthalmologischen Gesellschaft 2008, 105(10):965-975; quiz 976-967.

6. Viestenz A, Schrader W, Kuchle M, Walter S, Behrens-Baumann W: [Management of a ruptured globe]. Der Ophthalmologe : Zeitschrift der Deutschen Ophthalmologischen Gesellschaft 2008, 105(12):1163-1174; quiz 1175.

7. Colby K: Management of open globe injuries. International ophthalmology clinics 1999, 39(1):59-69.

8. Agrawal R, Wei HS, Teoh S: Prognostic factors for open globe injuries and correlation of ocular trauma score at a tertiary referral eye care centre in Singapore. Indian journal of ophthalmology 2013, 61(9):502-506.

9. Dannenberg AL, Parver LM, Brechner RJ, Khoo L: Penetration eye injuries in the workplace. The National Eye Trauma System Registry. Archives of ophthalmology 1992, 110(6):843-848.

10. Entezari M, Rabei HM, Badalabadi MM, Mohebbi M: Visual outcome and ocular survival in openglobe injuries. Injury 2006, 37(7):633-637.

11. Kuhn F, Morris R, Witherspoon CD, Heimann K, Jeffers JB, Treister G: A standardized classification of ocular trauma. Ophthalmology 1996, 103(2):240-243.

12. Kuhn F, Maisiak R, Mann L, Mester V, Morris R, Witherspoon CD: The Ocular Trauma Score (OTS). Ophthalmology clinics of North America 2002, 15(2):163-165, vi.

13. Kuhn F, Morris R, Witherspoon CD, Mester V: The Birmingham Eye Trauma Terminology system (BETT). Journal francais d'ophtalmologie 2004, 27(2):206-210.

14. Pieramici DJ, MacCumber MW, Humayun MU, Marsh MJ, de Juan E, Jr.: Open-globe injury. Update on types of injuries and visual results. Ophthalmology 1996, 103(11):1798-1803. 
15. Behrens-Baumann W: [Current therapy for postoperative endophthalmitis]. Klinische Monatsblatter fur Augenheilkunde 2008, 225(11):919-923.

16. Viestenz A, Schrader W, Behrens-Baumann W: [Traumatic Endophthalmitis Prevention Trial (TEPT)]. Klinische Monatsblatter fur Augenheilkunde 2008, 225(11):941-946.

17. Barry P B-BW, Pleyer U: Guidellines on prevention, investigation and management of postoperative endophthalmitis, vol. ISBN 0-9550988-0-7, S 1-33: European Soc for Cataract and Refractive Surgeons; 2008.

18. Rohrbach: Ophthalmologische Traumatologie: Schattauer, Stuttgart, New York; 2002.

19. Mayer CS, Loos DA: [Posttraumatic endophthalmitis : Complication following severe eye injury]. Der Ophthalmologe : Zeitschrift der Deutschen Ophthalmologischen Gesellschaft 2015.

\section{Tables}


Table 1

For a predictive value regarding functional outcome, initial visual acuity and additional variables are calculated into the OTS. It is mainly used as standard for the assessment of ocular trauma in the Anglo-Saxon countries.

\begin{tabular}{|ll|}
\hline Initial visual acuity in the affected eye & Raw points \\
\hline$>20 / 40$ & 100 points \\
\hline $20 / 50-20 / 200$ & 90 points \\
\hline $19 / 200-1 / 100$ & 80 points \\
\hline Hand movement or light perception & 70 points \\
\hline No light perception & 60 points \\
\hline Variables & Yes: -23 points / \\
\hline Globe rupture & No: 0 points \\
\hline Afferent pupillary defect (RAPD) & Yes: -10 points / \\
\hline Endophthalmitis 0 points \\
\hline Retinal detachment & Yes: -17 points / \\
\hline No: 0 points \\
\hline OTS Category & Yes: -11 points / \\
\hline Category 1 & No: 0 points \\
\hline Category 2 & Yes: -14 points / \\
\hline Category 3 & No: 0 points \\
\hline Category 4 & 66 to 80 points \\
\hline Category 5 & 92 to 100 Points \\
\hline
\end{tabular}


Table 2

Patients' characteristics, age groups and percentage of work related accidents

\begin{tabular}{|lll|}
\hline No. of subjects & $\mathrm{n}=147$ \\
\hline \multirow{2}{*}{ Gender } & male & $115(78.2 \%)$ \\
\cline { 2 - 3 } & female & $32(21.8 \%)$ \\
\hline \multirow{2}{*}{ Age (years) } & 1-20 (children and adolescents) & $27(18.4 \%)$ \\
& Right & $75(51.0 \%)$ \\
& Left & $42.9 \pm 22.2$ years \\
& 65 (seniors) & $98(66.7 \%)$ \\
& mean & $22(15.0 \%)$ \\
\hline & nork related accidents & $54(36.7 \%)$ \\
\hline
\end{tabular}


Table 3

Classification of the open globe injury

\begin{tabular}{|c|c|c|c|}
\hline \multirow[t]{5}{*}{ Type (Mechanism of injury) } & A & Rupture & $\begin{array}{l}44 \\
(29.9 \%)\end{array}$ \\
\hline & B & Penetration & \multirow{2}{*}{$\begin{array}{l}58 \\
(39.5 \%)\end{array}$} \\
\hline & C & Intraocular foreign body & \\
\hline & \multirow[t]{2}{*}{ D } & \multirow[t]{2}{*}{ Perforation } & $\begin{array}{l}38 \\
(25.9 \%)\end{array}$ \\
\hline & & & $7(4.8 \%)$ \\
\hline \multirow{8}{*}{$\begin{array}{l}\text { Grade (initial visual acuity before } \\
\text { surgery) }\end{array}$} & 1 & $>20 / 40$ & \multirow{2}{*}{$\begin{array}{l}29 \\
(19.7 \%)\end{array}$} \\
\hline & 2 & $20 / 50$ to $20 / 100$ & \\
\hline & 3 & $19 / 100$ to $5 / 200$ & $\begin{array}{l}23 \\
(15.6 \%)\end{array}$ \\
\hline & 4 & $4 / 200$ to light perception & \multirow{2}{*}{$\begin{array}{l}25 \\
(17.0 \%)\end{array}$} \\
\hline & 5 & NLP & \\
\hline & 6 & Not known & $\begin{array}{l}53 \\
(36.1 \%)\end{array}$ \\
\hline & & & $\begin{array}{l}16 \\
(10.9 \%)\end{array}$ \\
\hline & & & $\begin{array}{l}1 \\
(0.7 \%)\end{array}$ \\
\hline \multirow[t]{5}{*}{ Zone (location of the wound) } & & I Cornea (cornea +, sclera -) & 76 \\
\hline & & $\begin{array}{l}\text { Il Limbus to } 5 \mathrm{~mm} \text { posterior into sclera } \\
(\text { sclera }+, \mathrm{NH}-)\end{array}$ & \multirow{2}{*}{22} \\
\hline & & $\begin{array}{l}\text { III posterior to } 5 \mathrm{~mm} \text { from limbus (sclera }+ \text {, } \\
\mathrm{NH}+\text { ) }\end{array}$ & \\
\hline & & Not known & $\begin{array}{l}47 \\
(32.0 \%)\end{array}$ \\
\hline & & & $2(1.3 \%)$ \\
\hline \multirow[t]{6}{*}{ OTS Category } & & Category 1 (worst prognosis) & $\begin{array}{l}40 \\
(272 \%)\end{array}$ \\
\hline & & Category 2 & \multirow{2}{*}{$\begin{array}{l}46 \\
(31.3 \%)\end{array}$} \\
\hline & & Category 3 & \\
\hline & & Category 4 & $\begin{array}{l}40 \\
(27.2 \%)\end{array}$ \\
\hline & & Category 5 (best prognosis) & $\begin{array}{l}21 \\
(14.3 \%)\end{array}$ \\
\hline & & & 0 \\
\hline
\end{tabular}


Table 4

Detailed injury characteristics and types of intraocular foreign body material

\begin{tabular}{|c|c|c|}
\hline \multirow[t]{12}{*}{ Injured and damaged structures of the eye } & Eyelids & 26 (17.7\%) \\
\hline & Cornea & $110(74.8 \%)$ \\
\hline & Iris & $94(63.9 \%)$ \\
\hline & Lens & $83(56.5 \%)$ \\
\hline & Sclera & $71(48.3 \%)$ \\
\hline & Retina & $70(47.6 \%)$ \\
\hline & Optic nerve & $29(19.7 \%)$ \\
\hline & Vitreous & $88(59.9 \%)$ \\
\hline & Normal vitreous & $59(40.1 \%)$ \\
\hline & Vitreous Hemorrhage & $36(24.5 \%)$ \\
\hline & Endophthalmitis & $2(1.4 \%)$ \\
\hline & Vitreous loss & $50(34.0 \%)$ \\
\hline \multirow[t]{4}{*}{ Intraocular foreign body (IOFB) material } & Metal & $32(84.2 \%)$ \\
\hline & Glass & $4(10.5 \%)$ \\
\hline & Plastic & 0 \\
\hline & Organic material & $2(5.3 \%)$ \\
\hline \multirow[t]{2}{*}{ Foreign body removed successfully } & Yes & $36(94.7 \%)$ \\
\hline & No & $2(5.3 \%)$ \\
\hline \multirow[t]{7}{*}{ Surgical care of affected structures in the eye } & Lid Yes / No & $26 / 0$ \\
\hline & Cornea Yes / No & $107 / 3$ \\
\hline & Sklera Yes / No & $68 / 3$ \\
\hline & Iris Yes / No & $69 / 24,1$ not known \\
\hline & Lens extraction Yes / No & $62 / 21$ \\
\hline & Vitrectomy Yes / No & $71 / 17$ \\
\hline & Retina Yes / No & $47 / 23$ \\
\hline
\end{tabular}



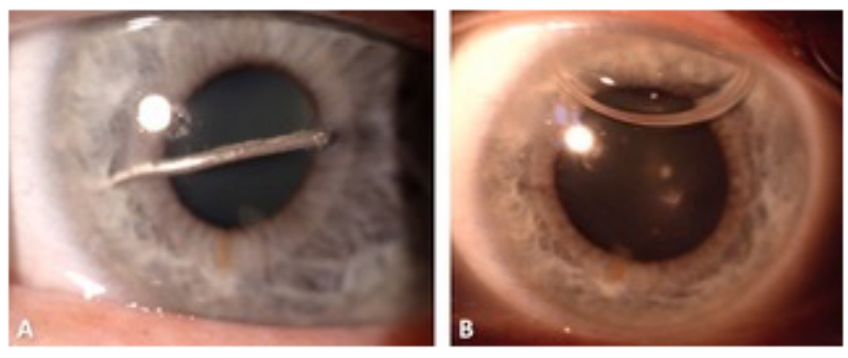

Figure 1

Zone I injury with corneal penetration by a nail. Before (A) and after surgery (B).
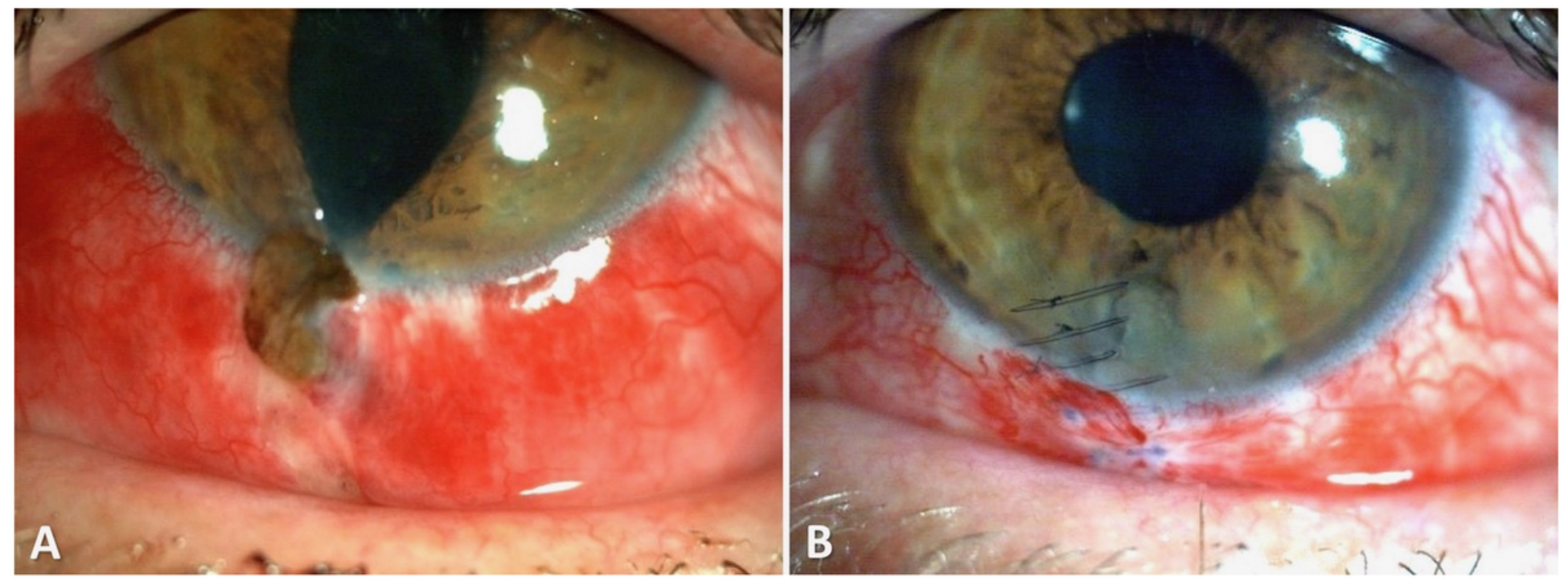

\section{Figure 2}

Example of a zone II open globe injury: Corneal dehiscence caused by a broken goggle with a consecutive iris prolapse. Setting before surgery (A) and after iris reposition and wound closure (B).

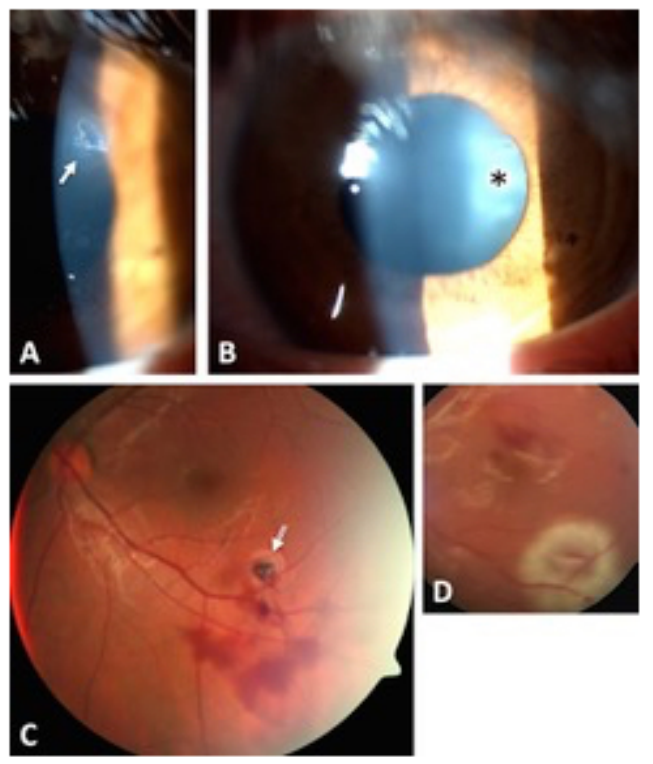

Figure 3 
One case with a zone II injury. Penetration of a foreign body at the limbus. Open globe injury with small corneal entrance wound (A), punctured lens $(B)$ and retinal impact $(C)$ by a small metallic foreign body (arrow). Intraoperative situation after removal of the foreign body, laser-retinopexy and silicone-oil filling (D).

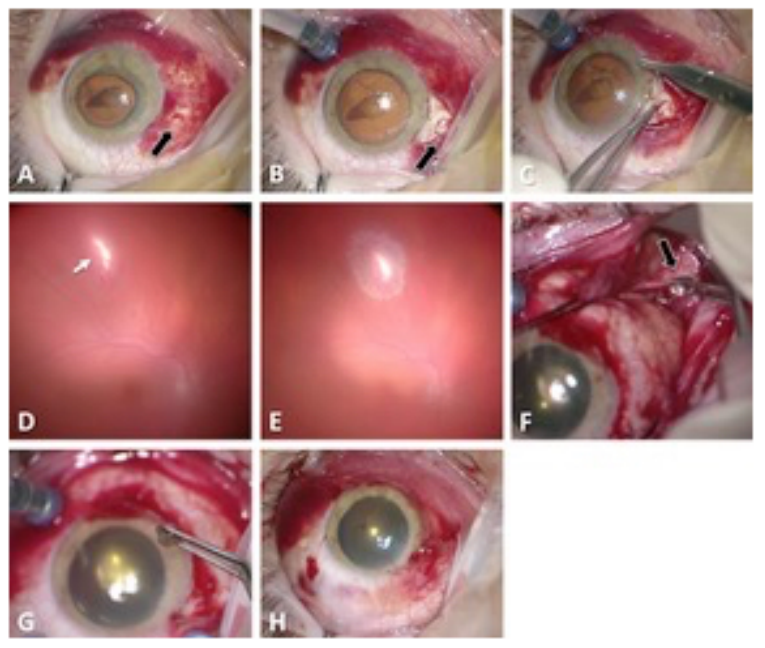

Figure 4

Zone III perforating open globe injury: Preoperative findings of the anterior segment with a self-closed entry of the foreign body $2 \mathrm{~mm}$ posterior the corneo-scleral border (A-C). Vitrectomy and intraoperative situation ( $D$ and $E$ ): After removing the vitreous hemorrhage, a secondary posterior laceration is revealed. The foreign body is not detectable from inside. Additional opening of the conjunctiva and inspection of the posterior sclera $(\mathrm{F})$. Removal of the foreign body located at the posterior pole. End of surgery $(\mathrm{G})$.

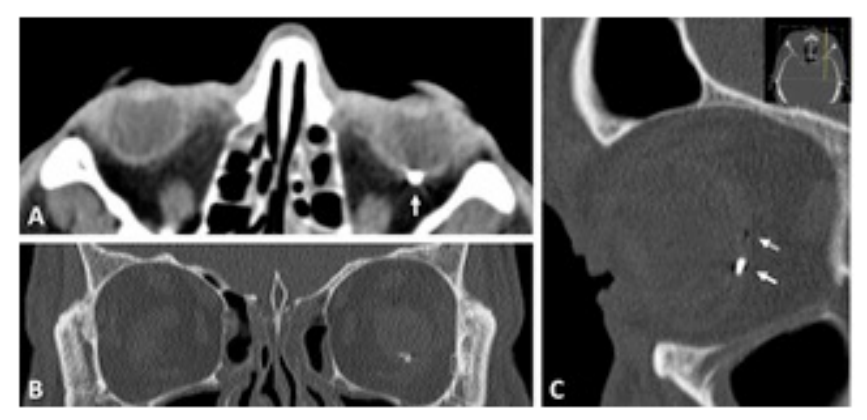

Figure 5

Computed tomographic images from the same patient mentioned in Figure 4. Frontal (A), axial (B) and sagittal (C) images, location of the metallic foreign body at the posterior pole. 